\title{
Erratum zu: Evidenzbasierte Strukturierung und Bewertung empirischer Forschung im Requirements Engineering
}

\section{Grundlagen, Ordnungsrahmen, Forschungslandkarte}

DOI 10.1007/s11576-010-0235-1

\section{Die Autoren}

Prof. Dr. Matthias Goeken (JP) ( $\varangle)$ Dipl.-Kfm. Janusch Patas IT-Governance-Practice-Network Frankfurt School of Finance \& Management Sonnemannstraße 9-11 60314 Frankfurt am Main Deutschland m.goeken@frankfurt-school.de j.patas@frankfurt-school.de
Online publiziert: 2010-08-27

Die Online-Version des Originalartikels können Sie unter doi: 10.1007/s11576-010-0223-5 finden.

(C) Gabler Verlag 2010
WIRTSCHAFTSINFORMATIK (2010) 52(3): 173-184

Abbildung 2 auf Seite 179 ist infolge eines technischen Fehlers leider unvollständig veröffentlicht worden. Die korrekte $\mathrm{Ab}$ bildung ist hier wiedergegeben. Wir bitten, den Fehler zu entschuldigen.

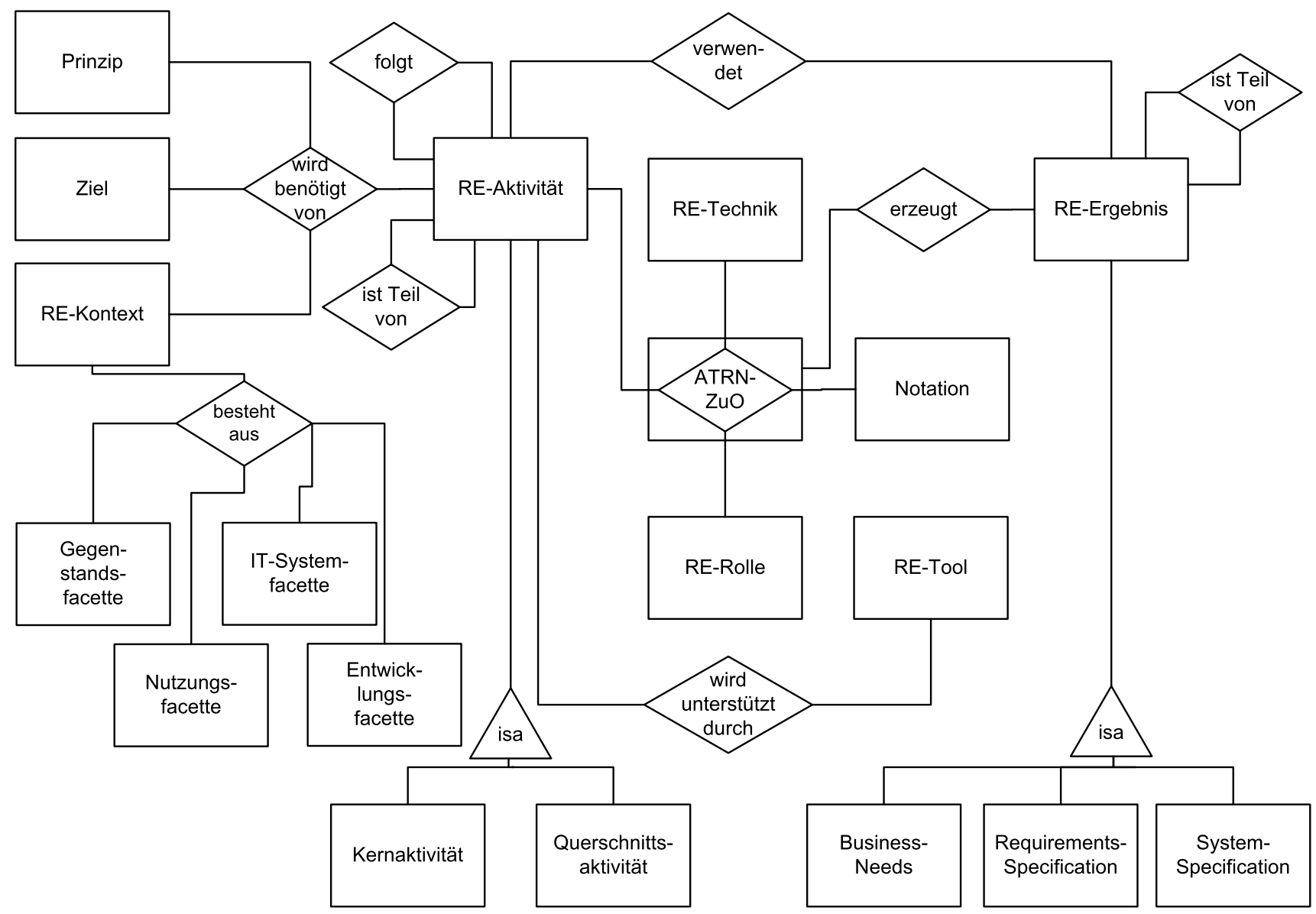

Abb. 2 Ordnungsrahmen zur Strukturierung empirischer Forschung im RE 